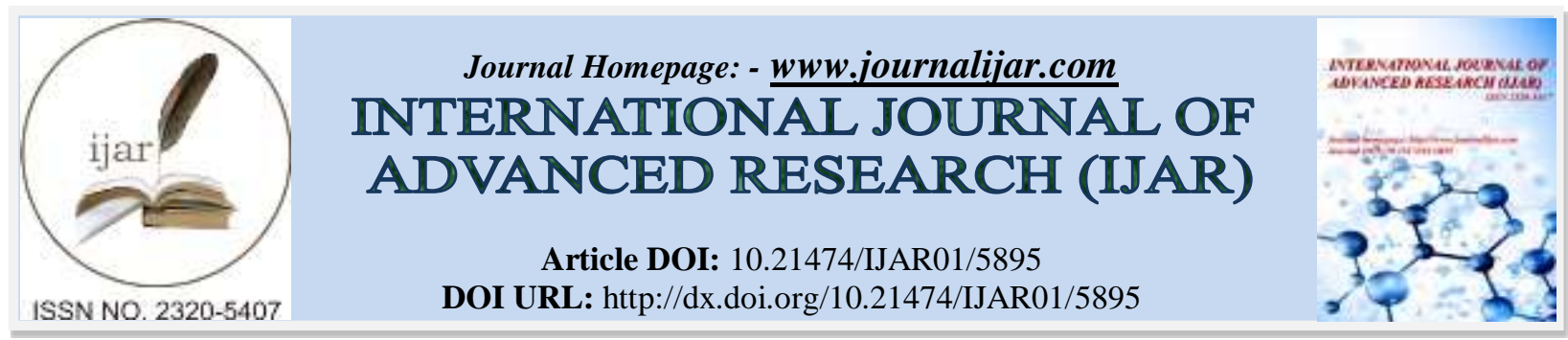

RESEARCH ARTICLE

\title{
INFLUENCE OF AGRICULTURAL PRODUCTS' VALUE ADDITION STRATEGIES ON THE GROWTH OF RURAL WOMEN ENTREPRENEURSHIP: A STUDY OF SELECTED COUNTIES IN WESTERN KENYA.
}

Rozilla Adhiambo, Professor Maria Onyango and Dr. Vitalis Mogwambo. Management and economics jaramogi oginga odinga university of science and technology Kenya.

\section{Manuscript Info}

Manuscript History

Received: 17 September 2017

Final Accepted: 19 October 2017

Published: November 2017

Key words:-

products, value addition, , and entrepreneurship

\section{Abstract}

Promotion of Women's economic empowerment is widely viewed in literature as the force behind poverty reduction and economic growth. Majority of donor support is directed at promoting food security in rural areas of counties. Farmer Support projects in Kenya are aimed at growth of women small enterprises. However, emphasis on female entrepreneurship growth appear sparse. Rural agriculture is highly feminized but women's contribution in economic indices is not visible. Economic survey, Kenya (2007), showed for example that out of the 160,000 tons of sorghum produced nationally, animal feeds account for $10 \%$, seeds $1.9 \%$, milling $23 \%$, food $53.6 \%$ and the rest is wastage after production. This study aimed at determining the influence of value addition strategies of agricultural products' on growth of rural women entrepreneurship. The study was guided by the following objectives: to investigate the agricultural products' processing strategies that promote rural women entrepreneurship in western Kenya; to establish the agricultural products' packaging strategies for food products that promote rural women entrepreneurship in western Kenya; The study targeted 1,625 rural women entrepreneurs from Homa bay, Vihiga, Siaya and Kisii counties respectively out of which 487 were selected as the sample size. Key respondents were purposively selected and comprised of 5 staff from the department of agriculture, 2 from Agriculture Strategy Development Support programme (ASDSP) and 1 from a non-governmental organization. Quantitative data was collected using questionnaires, while interview schedules observation schedules and focus group discussions were used to collect qualitative data. Data was analyzed using computer aided software and presented in descriptive and inferential statistics. The finding was that $90.3 \%$ of the rural women mainly use sorting and cleaning as a processing method among a range of other methods, technology is used by $40.6 \%$ to add value, processed products fetch an average of $10,000 \mathrm{kshs}$ monthly for $88.4 \%$ of the rural women entreperenuers involved in processing agricultural products, $83.7 \%$ process based on customer taste and preferences while $71 \%$ use knowledge from others to add value. The analysis revealed highly significant $(\mathrm{p}<0.05)$ positive relationship between agricultural products processing strategies and growth of rural women 
entrepreneurship in western Kenya. On packaging, 92.4\% use polythene bags and this increases their profits as indicated by $92.0 \%$ of the rural women entreperenuers, however the cost of packaging is high for $91 \% \%$. The source of the packaging is other companies for $96.9 \%$ rural women entreperenuers and only5.2\% design their own packaging. Trainings on packaging knowledge added value for $96.7 \%$ of rural women entreperenuers. The analysis revealed highly significant ( $\mathrm{p}<$ 0.05 ) positive relationship between packaging strategies and growth of rural women entrepreneurship. The study concludes that processing and packaging are value addition strategies that influence growth of rural women entrepreneurship. The study recommends that technology friendly to rural women entreperenuers should be availed to them to enhance value addition strategies. Rural women should also be supported to develop more environment friendly packages to further add value to their products. Future studies should establish the influence of social media on growth of rural women entrepreneurship.

Copy Right, IJAR, 2017,. All rights reserved.

\section{Introduction:- \\ Definition of Entrepreneurship:-}

Vale added agriculture entails changing a raw agricultural product into something new through packaging, processing, cooling, drying, extracting or any other type of process that differentiates the product from the original raw commodity to a more valuable one. Value-added agriculture is an important strategy to both agricultural entrepreneurship and rural development (Coltrain, Barton and Boland, 2000; Kilkenny and Schluter, 2001; Womach, 2005). The concept of value addition by Food and Agriculture Organization (FAO) is such that value can be added to an intermediate Agri-food product not only by processing it, but also by storing it (value increasing over time) and transporting it (value increasing over space). The increased demand of prepackaged and prepared foods has contributed to the rise of food processors as lead firms in Agri-food value chains with recognizable brands and large processing and buying power (Humphrey and Young and Hobbs, 2006). For value chain stakeholders, value added is defined as the difference between the non-labour costs incurred to produce and deliver a food product and the maximum price the consumer is willing to pay for it (Neven, 2014).

The Value chain concept was first developed in the manufacturing industry in the USA in mid 1980s as an instrument for identifying the value of each step in the production process (Mrema \& Ndikumana, 2013). Valueadded agriculture can only be achieved when farmers are able to supply the market with products carrying form, space, time, quality, functionality, and identity characteristics for which consumers are willing to pay a premium over raw generic commodities without these characteristic, (Ruoxi Lu \& Dudensing, 2015).

Entrepreneurship in agriculture is a concept which has recently received considerable interest among policy makers and development practitioners as a means to spurring rural socio-economic development (Envick \& Mullen, 2015). The rate of entrepreneurial activity among women continues to increase worldwide as value and new product development are essential for survival of enterprises in today's business environment (De Bruin, Brush and Welterl, 2006). Women managed Small and medium enterprises (SMEs) are more dominant within the business environment compared to the large and well established companies continually searching for new platforms and methods to market their products.

The SMEs need to have very efficient product development practices. This will maximize the limited resources available to improve the quality of products by transforming a raw product into a valuable form in the market (Envick \& Mullen, 2015).

Agricultural development in Africa has largely been dominated by on farm production issues. The agricultural development paradigm in the 1950s and 60s in the Eastern Africa region was mainly on improving household food self-sufficiency especially for the over $85 \%$ of the population then living in rural areas as peasant subsistence farmers. While $75 \%$ of the agricultural work is done by women (Prakash, 2003) evidence reveals that gross domestic product is dominated by small farms whose success depends on entrepreneurial process which is adopted 
at various levels of production (Apata, 2015). The focus on the influence of processing and packaging as value addition strategies on growth of rural women entrepreneurship is a gap that has been filled by this study.

In West Africa, low-cost, traditional food processing techniques are the bedrock of small-scale food processing enterprises that are crucial to rural development in West Africa. The small- scale food industries generate employment opportunities which reduce rural-urban migration. Barriers that impact on rapid growth and development of small-scale food industries in West Africa include adoption of inefficient and inappropriate food processing technologies, and inefficient post-harvest handling practices, inadequate capital, and low profit margins (Aworh, 2008). This has provided an opportunity for this research that has generated more knowledge on the influence of processing and packaging as value addition strategies on rural women entrepreneurship.

However, it is estimated that about $50 \%$ of perishable food commodities including fruits, vegetables, roots and tubers and about $30 \%$ of food grains are lost after harvest in West Africa. Progress has been realized in upgrading traditional West African food processing technologies including the mechanization of fermented cassava meal processing, the production of instant yam flour or flakes, the production of soyogi (a protein-enriched complementary food), the industrial production of dawadawa (a fermented condiment) and the upgrading of a traditional roasted dry meat product. Traditional technologies of food processing form part of the culture of the people and the indigenous knowledge is handed down from parent to child over several generations (Aworh, 2008). This shows that culture is an environmental factor that contributes to the diffusion of knowledge on food processing strategies.

At independence, in early 1960s all the five East African Community (EAC) countries inherited a dual agricultural sector with a relatively efficient large scale commercial farming sub sector dominated by settlers and a rather basic traditional sector dominated by peasant farmers largely producing for their own subsistence. The commercial sector developed linkages with the markets either in the urban areas of the region for food crops or the global market for the cash crops. All the cash crops had to undergo primary processing in the region before exportation. The Large Scale Farmers, (LSFs) did the primary processing either on their own farms, through established agro industries to process their produce linked by their own cooperatives or through companies established for this purpose (Unga limited for grain milling, East Africa Tobacco for tobacco processing etc.). Other players active in post- harvest processing and value addition in the region were involved either in direct production and processing or in commodity marketing. Many small and medium companies were involved in grain milling, oil seed processing; processing of livestock products, forestry and timber products

Kenya has a large agro-processing industry, reflecting the importance of the agricultural sector in the Kenyan economy. . All these companies played and continue to play a key role in the post-harvest systems and employed thousands of workers throughout the region (Mrema et al, 2013).

Kenya Vision 2030 identifies agriculture as a key sector through which annual economic growth rates of 10 percent can be achieved. In the Vision, smallholder agriculture should transform from subsistence activities, low productivity to value addition, for 'an innovative, commercially-oriented, internationally competitive and modern agricultural sector. According to the National Agribusiness strategy, the global exposure could provide an opportunity to be exposed to international standards and develop highly valued food products that fetch a higher income (Government of Kenya, 2012).

Agriculture has remained a source of livelihood for 61 percent of Kenya's population who live in rural areas. Kenya's agricultural sector directly influences overall economic performance through its contribution to Gross Domestic product (GDP). The sector contributes to 30 percent of the GDP, 80 percent of the national employment, 60 percent of the total export earnings and provides for most of the country's food requirements. (Government of Kenya, 1999). Through agribusiness, possibilities of creating jobs in value-adding and agro-processing activities are very high (Orinda, 2013). This study has established that legal policies pertaining to value addition of other food products and whether they are being enforced is silent and has not featured clearly during trainings attended by women entrepreneurs.

Western Kenya is endowed with rich resources in land, climate and soils therefore relies on agriculture as a main source of livelihood. The poverty index is approximated on average at $49.9 \%$ according to the Economic Survey report (GOK, 2005). Value addition on farm produce is a key strategy to commercialize farming for small holder 
farmers in western Kenya. The sweet potato value addition for instance has the potential of increasing farmers' income. The African leafy vegetables are also widely grown in western Kenya and should be promoted and improved as commercial crops (Abukutsa, 2007). A stronger food productivity base offers a good opportunity for a broader economic growth and poverty reduction through various value addition strategies in western Kenya. In order to realize the impact, there must be a transformation involving a shift from subsistence-oriented household production and household-based agro-industry towards a modern integrated rural economy. Furthermore, the offfarm activities of the agribusiness and food retailing system, expand based on farm-level production, both in terms of value added and employment (Komarwa, 2011).

The Kenyan government has created institutions such as Kenya Agricultural Research Institute (KARI), Kenya Agricultural Productivity Programme (KAPP) and Traditional Food Crops Project (TFCP) to help farmers in value addition in the agricultural sector (Ntale, Litondo, and Mapopa, 2014). Attempts to add value to food production in Kenya includes the Kenyan Government and private sector improving packaging by means of legal Notice No 44 of 2005 and No 113 of 2008, which specify packaging material suitable for agricultural products. The current policy enforcement has been a ban on use of polythene paper for packaging which is bound to impact on rural women entrepreneurship.

Literature Review:-

Agricultural Product Processing and Growth of Entrepreneurship:-

A study by Alam \& Jani \&Senik \& Domil, (2011) in Malaysia sought to examine barriers of food process based small and medium scale manufacturing firms' growth in Malaysia. The methodology-utilized a quantitative methodology using a survey questionnaire mailed to $500 \mathrm{SME}$ food processing companies who were contact persons, managers or owners of the business. The finding was that financial barriers have the most important impact on the SMEs growth. Alam et al (2011), collected valuable information through the gathering of data and measurement of the major barriers of growth but the sample was not large enough as compared to the large number of food and beverages SMEs in the entire Malaysia including those in the rural areas to derive a conclusive analysis on the results. The divergence is that this study has established the influence of processing on growth of rural women entrepreneurship.

Chagomoka \& Afari-sefa \& Pitoro (2013) study in Malawi and Mozambique aimed at understanding the interactions among various actors in the value chain so as to be able to improve marketing efficiency by adding value to produce. The study methodology was based on a multistage cross-sectional primary data of respondents in Malawi and Mozambique. The study employed participatory evaluation and market research of a wide range of indigenous vegetable value chain to identify potential outlets and target crops and also to define processes of the value chains. The finding of the study was that $12 \%$ of respondents in Malawi and $6 \%$ of respondents in Mozambique process their indigenous vegetables. Chagomoka et al (2013) study showed an attempt to establish the importance of processing for value addition but linked it with value chain processes and not enterprise growth. This study has established specific value addition strategies by rural women entrepreneurs that influence on growth of their enterprises.

Ntale et al (2014) study investigated the factors that influence value addition on small farms in Kenya. The study employed a cross-sectional survey design and a multi-stage sampling technique where locations from Kiambu and Murang'a counties were identified. Farms were elected by line transect technique. Descriptive statistics was used to estimate the extent of value addition in Agri- businesses on small farms. Linear Probability Model (LPM), Logit, and Probit models were used to estimate the determinants of value addition on the small farms. The study revealed that Kenya's agrarian economy is suffering from limited value addition as the statistics showed that due to financial limitations, only $6 \%$ of small farmers added value to their agricultural produce ( $2 \%$ stored their products in granaries, $2 \%$ of them were processing and another $2 \%$ were packaging their products). The divergence is that Ntale et al (2014) focused on factors that influence value addition while this study has assessed value addition strategies' influence on growth of rural entrepreneurship in western Kenya.

\section{Agricultural Products' Packaging and Growth of Entrepreneurship:-}

A study by Silayoi and Speece (2006) in Thailand sought to establish the importance of packaging attributes. This study used conjoint analysis method to examine the relative importance of packaging elements in enhancing consumer perception. Conjoint analysis has been widely used in marketing to evaluate consumer preferences for products and services (Hair et al, 1998). The findings indicated that perceptions about packaging technology 
(portraying convenience) play the most important role overall in consumer likelihood to buy. The finding of the study was that elements such as shape, size, and colour of packages are instrumental in attracting customers to purchase The divergence of Silayoi et al (2006) with this study is considering packaging of agricultural products as a value addition strategy that influences growth of rural enterprises.

Hussain \& Ali \& Ibrahim \& Noreen \&Ahmad (2015) study focused on the influence of packaging over consumer buying behavior. The objective of this research was to establish elements behind the success of product packaging. Questionnaires were distributed to customers in different parts of Pakistan and used SPSS software to interpret the correlation and regression analysis. The research finding was that packaging and communication information about the product are important elements for the consumer buying behavior. The finding concurs with this study on packaging attracting customers, however, packaging has been considered a value addition strategy that influences growth of rural enterprises. This study collected views of rural women entrepreneurs involved in packaging to establish how packaging is working for them to grow their enterprises while Hussain et al collected data from consumers.

Study by Ugonna \&Jolaoso \& Onwualu (2015) study focus was on development of tomato value chain in Nigeria. The methodology used semi-structured informal interviews with key value chain actors including: input suppliers, farmers, producers, intermediate traders, wholesalers, retailers, processors and end users. The finding was that the tomato processing factories lacked appropriate packaging materials as fresh tomatoes were packed in baskets for transportation to the market and end up being stacked on top of each other, resulting in many injured fruit and profit losses. Study by Ugonna, et al (2015) study finding was an indication that appropriate packaging is important as a value addition strategy to increase profitability and this concurs with this study that has further related this with rural women entrepreneurial growth.

JICA (2012) study had the objective to identify institutions in Kenya that offer food packaging related trainings as a resource base for the One Village One Product (OVOP) groups in Kenya. The finding was that there is no national packaging directory where packaging producers and converters, importers, printers, equipment suppliers and designers can easily be accessed not only by OVOP groups but by other stakeholders as well. JICA, (2012) study focused on packaging as a value addition strategy but did not link it to growth of rural women enterprises in the villages. This study has filled in the gap by linking various agricultural products' packaging strategies to growth of enterprises in the rural areas.

A study commissioned by Deutsche Gesellschaft für Internationale Zusammenarbeit (GIZ) (2013), focused on food loss in the harvesting, processing and marketing stages. Its main aim was to improve data availability on food loss as an important food value chain in Kenya. General data for the study were collected from published sources and through key informants, and specific data through questionnaires and group discussions. A randomized survey was used so that statistically reliable quantitative data could be obtained on losses at the defined critical points. Multistage sampling was employed to include different regions and types of farmer, broker and trader in the survey. The survey results showed, extended bags have severe impacts on the price of potatoes as the produce is paid for per bag rather than per kilogram and bag sizes vary, even within the same categories. The study commissioned by GIZ, (2013 was able to effectively establish that packaging influences pricing, however, the influence on growth of rural women entrepreneurship was excluded. This study has established that there are costs associated with accessing a variety of packaging materials and this increases value to the agricultural products which has a positive influence on growth of rural women entrepreneurship.

\section{Material and Methods:- \\ Study Area:-}

This study targeted 4 out of 10 counties in the western region of Kenya with the aim of trying to establish the influence of agricultural products' value addition strategies namely processing and packaging on growth of rural women entrepreneurs. In addition, extension workers in the Government organizations such as those working under the Ministry of agriculture specifically department of agriculture and livestock and Agriculture strategy development support programme (ASDSP) with a focus on value addition were targeted in this study to provide a more elaborate view of the link with rural women entrepreneurship. The locational context of the study was rural based. Rural areas have been known to lack adequate capital, networks, sufficient labour markets, information, and have limited access to technology and infrastructure, which inhibits entrepreneurial activity (Acs and Malecki, 2003; Stathapoulou, Psaltopoulos and Skuras, 2004). 


\section{Limitations and Delimitations of the Study:-}

The study was focused on Siaya, Vihiga, Homa Bay and Kisii Counties within western Kenya, therefore, this study was limited to this geographical region. The study was on women entrepreneurs dealing on food and cash crops production, thus this study was gender limited. The study was limited to agricultural products value addition strategies and growth of women entrepreneurship with a time frame of between 2016 and 2017. The researcher therefore conducted the study to contribute to concerted efforts to uplift the communities' living standards by generating new knowledge on approaches to strategic value addition of agricultural products for promotion of entrepreneurship. Data analysis was limited to frequency counts, percentages, cross tabulations to establish relationships and correlations to further establish relationships of variables.

\section{Research Methodology:-}

This study used cross sectional survey design that explains the purpose of conducting a survey as being descriptive, explanatory or exploratory (Martella \& Nelson, \& Marchand, 1999). The design involved collection and analysis of data in a way that focused on combining relevance to the purpose of the research (Kothari, 2004).

Both quantitative and qualitative methods of collecting data were used. The major emphasis was to establish more ideas and insights and familiarity on the influence of agricultural products' value addition strategies on growth of rural women entrepreneurship growth with regards to the interplay between the micro environment and macro environment where there are institutions providing various forms of support. The target population were rural women entrepreneurs in the counties of Siaya, Homa Bay, Vihiga and Kisii and based on the large amount of food crops that they produce.

\section{Sample Size and Sampling Technique:-}

The sample size was 487 respondents. According to Mugenda \& Mugenda (2003) a sample size of between 10 and $30 \%$ is a good representation of the target population in data collection. Simple random technique was used to identify the respondents. The sampling frame comprised of entrepreneurs involved in value addition of groundnuts, sweet potatoes, sugarcane, indigenous vegetables, mangoes, bananas and poultry. Key informants were selected through purposive sampling and snowballing methods for interview. The researcher was able to learn that mandates of agriculture players were not homogenous across the 4 counties. For this reason the key respondents targeted varied in the counties. They comprised of 5 officers from the department of agriculture, 2 Agriculture Strategy Development Support programme (ASDSP) staff, and 1 NGO staff responsible for agriculture.

\section{Data Collection:-}

Data was collected using quantitative and qualitative methods. The instruments used were questionnaires, schedule interviews, observation guides, and focus group discussions. The questionnaires and FGDs were administered on the respondents while the schedule interviews were administered on the key respondents. The researcher also collected data by making observations using the observation guide. Secondary data was collected from document reviews.

\section{Data analysis:-}

The study analyzed data using descriptive $s$ and inferential statistics. Contingency table and chi square was used to establish the relationship between each of the agricultural products' value addition strategy with determinants of entrepreneurial growth. Chi square also helped to test the hypotheses of the study using the following formula:

\section{$\chi 2=\underline{\text { Extent to } \text { which frequencies are not consistent with the null hypothesis }}$ \\ Size of sample}

Pearson correlation of coefficient was used to analyze the relationship between cost incurred on value addition strategies as independent variables and access to finance and level of profitability as determinants of entrepreneurship growth. Correlation of coefficient has further been used to establish the linkages between agricultural products' value addition strategies and growth of women entrepreneurship to determine the positive and negative correlation. The researcher used a probabilistic model to predict the extent to which the identified independent variables affect the dependent variable. This has been represented by the following equation: $\mathrm{Y}=\beta \mathrm{o}+\beta 1 \mathrm{x} 1+\beta 2 \times 2+€$ 
Where;

$\mathrm{Y}=$ Rural women entrepreneurial growth- The dependent variable

$\beta$ =is a vector of parameters to be estimated,

and

$\beta 1=$ Agricultural products' Processing strategies - independent variable

$\beta 2=$ Agricultural products' Packaging strategies' - independent variable

$€=$ error variable which represents all the factors that affects the dependent variable

Findings and Discussions:-

Influence of Agricultural products' Processing Strategies on Growth of Rural Women Entrepreneurship:Below are responses that responded to the objective: To establish the influence of agricultural products' processing strategies on the growth of rural women entrepreneurship in western Kenya

Table 1:- Range of processes used by rural women entrepreneurs

\begin{tabular}{llllllllllll}
\hline & SA & $\%$ & $\mathbf{A}$ & $\mathbf{\%}$ & $\mathbf{N S}$ & $\mathbf{\%}$ & $\mathbf{D}$ & $\mathbf{\%}$ & $\mathbf{S D}$ & $\mathbf{\%}$ & MS \\
\hline Processing & & & & & & & & & & & \\
Methods & $\mathbf{N}$ & & $\mathbf{N}$ & & $\mathbf{N}$ & & $\mathbf{N}$ & & $\mathbf{N}$ & & \\
1. Drying & 370 & 85.5 & 34 & 7.9 & 6 & 1.4 & 8 & 1.8 & 15 & 3.5 & 4.7 \\
2. Juicing & 90 & 20.8 & 30 & 6.9 & 0 & 0 & 250 & 57.7 & 90 & 20.1 & 2.7 \\
$\begin{array}{l}\text { 3. Grinding } \\
\text { 4. Chopping into }\end{array}$ & 206 & 47.6 & 122 & 28.2 & 5 & 1.2 & 80 & 18.5 & 20 & 4.6 & 3.9 \\
$\quad \begin{array}{l}\text { Pieces } \\
\text { 5. Sorting and }\end{array}$ & 123 & 28.4 & 101 & 23.3 & 9 & 2.1 & 80 & 18.5 & 120 & 27.7 & 3.1 \\
$\quad$ Cleaning & 391 & 90.3 & 5 & 1.2 & 9 & 2.1 & 20 & 4.6 & 8 & 18.5 & 4.7 \\
\hline
\end{tabular}

Source: Author (2016)

Key: SA -Strongly Agree, A- Agree, NS-Not Sure, D-Disagree, SD -Strongly Disagree

N-Frequency, \% - Percent, MS-Mean Score

From Table 1, Sorting and cleaning is a method used by $90.3 \%$ of the respondents and is applicable in all the sectors. Grinding was a method strongly agreed on by $46.7 \%$ of the respondents while $85 \%$ of the respondents agreed that they use drying. $28.4 \%$ of the respondents strongly agreed that they chopped products into pieces to add value. $20.8 \%$ of the respondents strongly agreed that they used juicing process to add value while $57.7 \%$ disagreed.

The finding is that a range of processing methods are used but sorting and cleaning was the most widely used to add value to all food products. Ntale at al (2014) study revealed that Kenya's agrarian economy is suffering from limited value addition as the statistics showed that due to financial limitations, only $2 \%$ of them were processing. The point of convergence is that both studies focused on ago food processing in relation to enterprises however, this study has been able to establish that a range of agricultural products' processing methods are used as value addition strategy by all the respondents and the leading one is sorting and cleaning followed by grinding.

The study revealed that $68.5 \%$ of the rural women entreperenuers strongly agreed that they access technology for processing while $40.6 \%$ strongly agreed that they use technology. The finding is that access and use of technology adds value to processing of agricultural products' but some do not use the technology. The convergence with Wanga \& Mutuku \& Olubandwa (2009) was that the study assessed the use of technology and related it to quality of a product. The divergence is that besides access, this study has also assessed use of technology as adding value on agricultural products to influence growth of rural women entrepreneurship and not quality of product as Wanga et al (2009) study found out.

The study further revealed that processing agricultural products increases monetary value of between 5000$10,000 \mathrm{kshs}$ on a monthly basis as agreed by $70.9 \%$ of the respondents. Alam et al (2011) study finding was that financial barriers have the most important impact on the SMEs growth while the finding of this study is that processed agricultural products generate a monthly income and is profitable to the rural women entrepreneurs. This suggest that SMEs can grow if value is added on agricultural products through processing. 
The study also revealed that, $71.0 \%$ of the rural women entreperenuers learnt processing methods from other entrepreneurs. The finding was that knowledge sharing among the entrepreneurs enabled them to learn processing methods from one another. The agricultural products are processed based on customer taste and preferences as revealed by $83.7 \%$ of the rural women entrepreneurs in western Kenya. This concurs with a research by De Brentani \& Kleinschmidt, 2004; and Stewart-Knox \& Mitchell, (2003) finding that product success is dependent upon good understanding of consumer wants, needs and preferences and further established by Anderson and Hanselk study (2009) as key in building a profitable and substantial business.

\section{Pearson's coefficient of correlation analysis:-}

The Pearson Product-Moment correlation coefficient $(r=.854)$ computed indicated that there was high positive correlation between agricultural products' processing strategies and growth of rural women entrepreneurship in western Kenya. The analysis revealed highly significant $(\mathrm{p}<0.05)$ positive relationship between agricultural product processing strategies and growth of rural women entrepreneurship. Hence it is acceptable to conclude that processing agricultural products is a value addition strategy that positively contributes to growth of rural women entrepreneurship in western Kenya. Influence of Agricultural products' Packaging of food products on Growth of Rural Women Entrepreneurship:-

Below are responses on influence of agricultural product's' packaging as value addition and their influence on growth of rural women entrepreneurship.

Table 2:- Range of packages used for agricultural products

\begin{tabular}{|c|c|c|c|c|c|c|c|c|c|c|c|c|c|}
\hline \multirow{2}{*}{ Score } & \multirow{2}{*}{$\begin{array}{r}\mathbf{S A} \\
\mathbf{N}\end{array}$} & \multirow{2}{*}{$\begin{array}{c}\% \\
\mathbf{N}\end{array}$} & \multicolumn{2}{|c|}{$\mathbf{A}$} & $\%$ & \multirow{2}{*}{$\begin{array}{l}\mathbf{N S} \\
\mathbf{N}\end{array}$} & \multirow[t]{2}{*}{$\%$} & \multirow{2}{*}{$\begin{array}{c}\mathbf{D} \\
\mathbf{N}\end{array}$} & \multicolumn{2}{|c|}{$\%$} & \multirow[t]{2}{*}{ SD } & \multirow[t]{2}{*}{$\%$} & \multirow[t]{2}{*}{ Mean } \\
\hline & & & & $\mathbf{N}$ & & & & & & & & & \\
\hline 1. Boxes (plastic) & 280 & 64.7 & 10 & 2.3 & 0 & 0 & 60 & 13.9 & 50 & 11.5 & 3.7 & & \\
\hline 2. Baskets & 310 & 71.6 & 60 & 13.9 & 0 & 0 & 32 & 7.4 & 34 & 7.9 & 4.4 & & \\
\hline 3. Small basins & 291 & 67.2 & 30 & 6.9 & 0 & 0 & 6 & 1.4 & 5 & 1.2 & 3.7 & & \\
\hline 4. Plastic bottles & 98 & 22.6 & 20 & 4.6 & 0 & 0 & 230 & 53.1 & 85 & 19.6 & 2.6 & & \\
\hline 5. Cages & 160 & 36.9 & 40 & 9.2 & 0 & 0 & 105 & 24.2 & 128 & 29.6 & 2.9 & & \\
\hline 6. Gunny bags & 280 & 64.7 & 40 & 9.2 & 0 & 0 & 62 & 14.3 & 51 & 11.8 & 4.0 & & \\
\hline 7. Polythene & 375 & 86.6 & 25 & 5.8 & 0 & 0 & 20 & 4.6 & 13 & 3.0 & 4.7 & & \\
\hline
\end{tabular}

\section{Source: Author (2016)}

Key: SA -Strongly Agree, A- Agree, NS-Not Sure, D-Disagree, SD -Strongly Disagree

N-Frequency, $\%$ - Percent

The packaging listed in Table 2 are used in all the 4 counties. The most popular package is the use of polythene $86.6 \%$ strongly agree with only $3 \%$ in strong disagreement, this is followed by baskets $71.6 \%$, gunny bags and boxes by $64.7 \%, 67.2 \%$ strongly agreed they use small basins $71.6 \%$ strongly agreed they use baskets Plastic bottles are used by $22.6 \%$ to package, and $36.9 \%$ of respondents strongly agreed on using caging. The least packages used are plastic bottles, and caging. The finding was that various packages are used depending on the type of agricultural product, but the most commonly used was polythene paper. Study by Ugonna et al (2015) finding was that appropriate packaging was important as a value addition strategy to increase profitability, this concurs with the finding of this study that has further established that a variety of packaging are used to add value to agricultural products and influence growth of rural women entrepreneurship and they are mainly Primary packaging which is in direct contact with the product (e.g. a plastic bag containing groundnuts).

The study revealed that packaging agricultural products helps to increase profits as shown by $92.0 \%$ respondents who strongly agreed while only $2.3 \%$ disagreed. The finding was that packaging is a value addition strategy that fetches profits to rural women entrepreneurs. This corroborates ILO (2011) study finding that value adding off-farm activities in rural areas, such as packaging, increases the worth of a product and can increase the economic gains for rural producers.

The value of knowledge on packaging has made the entrepreneurs to attend trainings on packaging strategies as $96.7 \%$ agreed only $1.8 \%$ disagree while $1.3 \%$ are Not sure. The finding was that knowledge from trainings on packaging helped rural women entreperenuers to use appropriate packages as a result, adding value to agricultural products. This builds on the study by Ugonna et al (2015) finding that the tomato processing factories lacked 
appropriate packaging materials, resulting in many injured fruit and profit losses. This study has established that training on packaging strategies is important.

Table 3:- Sources of packaging by the entrepreneur

\begin{tabular}{|c|c|c|c|c|c|c|c|c|c|c|}
\hline SA & $\%$ & A & $\%$ & NS & $\%$ & D & $\%$ & SD $c$ & Me: & Score \\
\hline $\mathbf{N}$ & & & $\mathbf{N}$ & & $\mathbf{N}$ & & $\mathbf{N}$ & $\mathbf{N}$ & & \\
\hline 1. Other 164 & 37.8 & 256 & 59.1 & 9 & 2.0 & 4 & 1 & 0 & 0 & 4.34 Companies \\
\hline $\begin{array}{l}\text { 2. Design own } 4 \\
\text { Packaging }\end{array}$ & 1 & 4 & 1 & 9 & 2.0 & 55 & 12.7 & 361 & 83.3 & 1.23 \\
\hline
\end{tabular}

Source: Author (2016)

Key: SA -Strongly Agree, A- Agree, NS-Not Sure, D-Disagree, SD -Strongly Disagree

N-Frequency, \% - Percent

As shown in Table 3, 59.1\% agreed that they buy packaging from other companies, 37.8\% strongly agreed while $2.0 \%$ are Not Sure and $1 \%$ disagreed. The table 3 also shows that $83.3 \%$ strongly disagreed that they design their own packaging, $12.7 \%$ disagree, and $2.0 \%$ are Not sure while $1 \%$ strongly agree. This shows that entrepreneurs mainly source for packaging from other companies and very few have the capacity to design their own (only 1 $\%$.) This confirms a lack of capacity by rural women entreperenuers to design own packages. This study has established that designing own packages is low among rural women entreperenuers and they rely on packages from other manufacturers.

However, the study finding by JICA (2012), explained the reliance of enterprises on external source for packaging but established that there was no national packaging directory where packaging producers and converters, importers, printers, equipment suppliers and designers can easily be accessed by all stakeholders. JICA, (2012) study focused on packaging as a value addition strategy but did not link it to growth of rural women enterprises in the villages.

This study revealed that the rural women entreperenuers invest in packaging as $91.5 \%$ agreed that they spend between Kshs 2,000-3,000. The shows that packaging has a high cost implication as a value addition strategy for the rural women entrepreneurs.

The study further revealed that packaging material and design attracts customers from their counties to buy the agricultural products and $90.8 \%$ of the respondents agreed. The finding of the analysis showed that among all the packaging attributes, the packaging design and materials used has a significance as value addition. This corroborates Silayoi et al (2006,) study finding that visual attributes can potentially affect consumer purchase decisions. The study has added knowledge to Hussain et al (2015) study finding that packaging and communication information about the product are important elements for the consumer buying behavior. The finding was in tandem with this study, but has further considered packaging as a value addition strategy that influences growth of rural enterprises.

The Pearson Product-Moment correlation coefficient $(r=.956)$ computed indicated that there was highly positive correlation between packaging strategies and growth of rural women entrepreneurship in western Kenya. The analysis revealed highly significant $(\mathrm{p}<0.05)$ positive relationship between packaging strategies and growth of rural women entrepreneurship,. Hence it is acceptable to conclude that there were significant positive association between packaging as a value addition strategy and growth of rural women entrepreneurship in western Kenya.

Table 4:- Multiple Regression

\section{Variables Entered/Removed ${ }^{\text {a }}$}

\begin{tabular}{|l|l|l|l|}
\hline Model & Variables Entered & Variables Removed & Method \\
\hline 1 & $\begin{array}{l}\text { processing strategies, } \\
\text { Packaging strategies, }\end{array}$ & $\cdot$ & Enter \\
\hline a. Dependent Variable: Growth of rural women entrepreneurship \\
\hline b. All requested variables entered. \\
\hline
\end{tabular}


The next Table 4 shows the multiple linear regression model summary and overall fit statistics. It was found out that the adjusted $\mathrm{R}^{2}$ of our model is 0.933 with the $\mathrm{R}^{2}=.934$ that means that the linear regression explains $93.4 \%$ of the variance in the data.

Table 5:- Multi Linear Regression

\begin{tabular}{|c|c|c|c|c|}
\hline \multicolumn{5}{|c|}{ Model Summary } \\
\hline Model & $\mathrm{R}$ & R Square & Adjusted R Square & Std. Error of the Estimate \\
\hline 1 & $.966^{\mathrm{a}}$ & .934 & .933 & .314 \\
\hline
\end{tabular}

Due to the fact that the differences between $\mathrm{R}$ square and Adjusted $\mathrm{R}$ square is small (0.001) shows that the independent variables were precise.

Table 6:- Anova Analysis

\begin{tabular}{|l|l|l|l|l|l|l|}
\hline \multicolumn{2}{|l|}{ ANOVA $^{\mathbf{a}}$} \\
\hline Model & Sum of Squares & Df & Mean Square & F & Sig. \\
\hline \multirow{3}{*}{1} & Regression & 389.586 & 4 & 97.397 & 987.397 & $.000^{\mathrm{b}}$ \\
\cline { 2 - 7 } & Residual & 27.718 & 281 & .099 & & \\
\cline { 2 - 7 } & Total & 417.304 & 285 & & & \\
\hline
\end{tabular}

a. Dependent Variable: Growth of rural women entrepreneurship

b. Predictors: (Constant), Food processing strategies, Packaging strategies,

From the ANOVA Table6, it shows that all the independent variables which includes; agricultural product processing strategies and Packaging strategies helped to predict the Growth of rural women entrepreneurship, $(\mathrm{F}=$ 987.397, P (.0005). This implies that the null hypotheses were not useful hence reject the null hypotheses and accept the alternate hypotheses of the independent variables.

Table 7:- Coefficient of Analysis

\begin{tabular}{|c|c|c|c|c|c|}
\hline \multicolumn{6}{|l|}{ Coefficients $^{\mathrm{a}}$} \\
\hline \multirow[t]{2}{*}{ Model } & \multicolumn{2}{|c|}{ Unstandardized Coefficients } & \multirow{2}{*}{$\begin{array}{l}\text { Standardized } \\
\text { Coefficients } \\
\text { Beta }\end{array}$} & \multirow[t]{2}{*}{$\mathrm{T}$} & \multirow[t]{2}{*}{ Sig. } \\
\hline & B & Std. Error & & & \\
\hline (Constant) & .266 & .040 & & 6.603 & .000 \\
\hline $\begin{array}{l}\text { Agricultural product } \\
\text { processing strategies }\end{array}$ & .497 & .060 & .585 & 8.217 & .000 \\
\hline Packaging strategies & .185 & .075 & .484 & 2.480 & .014 \\
\hline
\end{tabular}

a. Dependent Variable: Growth of rural women entrepreneurship

From the findings in the multiple regression, Table 7, it shows that the independent variables which includes; agricultural product processing strategies and Packaging strategies, have predictive value for the dependent variable (Growth of rural women entrepreneurship) meaning they are all statistically significant hence the null hypotheses are rejected while accepting the alternate hypotheses since the $\mathrm{P}$ value is less than 0.05 .

From the Unstandardized Coefficients, the model predicts that increase in agricultural product processing strategies (.497) would results into increase in Growth of rural women entrepreneurship holding the other independent variable (Packaging strategies) constant. Moreover, increase in Packaging strategies (.185) would results into increase in Growth of rural women entrepreneurship holding the other independent variable (processing strategies) constant.

On the other hand, Beta expresses the relative importance of each independent variable in standardized terms. Firstly, the results shows that all the independent variables ( processing strategies and Packaging strategies) are significant predictors, secondly, it was established that processing strategies and Packaging strategies have a high impact (beta $=.585$ and beta $=.484$ ) respectively. In conclusion, these variables statistically significantly predicted Growth of rural women entrepreneurship. The two variables added statistically significantly to the prediction, $p<$ .05

Qualitative Presentation:-Various methods were used to collect qualitative data as explained below: Focus Group Discussions:- 
Record keeping was cited as a challenge due to lack of formal education by respondents during the focus group discussions (FGDs). Through the FGDs the respondents also revealed that apart from the need to access other basics for the family, they sell their value added products to recover costs incurred during production. On the status of the enterprises, the entrepreneurs have managed to source for funds from financial institutions but a lack financial management skills was cited during the FGDs.

Exposure visits exposed them to more knowledge and skills on agricultural products value addition strategies. The sorting method was done based on size and weight of the product to fetch higher incomes as further explained during FGD discussions. The poultry, (mainly chicken) 'were defeathered and chopped into pieces to make it easier to pack and provide a customer with an opportunity of choice on the parts they were interested in purchasing', according to the FGD respondents. FGDs in Kisii revealed that religion was a barrier especially to the entrepreneurs who ascribe to the Seventh Day Adventist (SDA) beliefs, for example processing banana into wine was disallowed. FGD respondents in Vihiga county explained that they use traditional methods for ripening bananas by placing them under the soil with ripe avocadoes, however the challenge 'is in realizing a uniform yellow colour that is clear of black spots after ripening'.

On packaging, FGDs revealed that Ritoke banana processors have further been exposed to international standards through visits to Bangkok and are making initiatives to conform in order to export their value added bananas, this is an indication of rural enterprise growth. During the FGDs, respondents explained that the colour of the package attracted customers. The ones that design their own are mainly used to pack groundnuts which they seal using candles as mentioned during FGDs in Vihiga, Kisii and Siaya counties. The FGDs in Siaya shared that they spend Kshs 3,120 for 102 plastic tins used to package peanut butter.

\section{Observation Guide:-}

The researcher observed a group of 5 women entrepreneurs who came in Kenya industrial research institute (KIRDI) to process groundnuts into peanut butter in Kisii County. KIRDI provided the infrastructure for processing food products at a minimal service fee. This has helped them expand their knowhow in use of processing technologies. The researcher observed that one had to wear a white overcoat before getting into the processing area, and used food gloves to handle the products for hygiene purposes. One entrepreneur travelled all the way from Migori town about 66.6 kilometres away to use the machines to process and package mango juice, and the researcher was informed that she does that monthly. The researcher also observed that the entreperenuers carried their own packages, as the facility only provided processing equipment. From observation the package for banana crisps was yellow in colour which blended with the natural colour of ripe bananas and Kisii County known for banana production as also mentioned by the respondents.

\section{Key Respondents:-}

According to the key respondents, the organizations that have been facilitating trainings and support in form of infrastructure and equipment through women in groups including facilitating exposure tours within and outside the counties, organizing field days, trade fairs, workshops and seminars include NGOs such as Kenya Agricultural value chain enterprises (KAVEs) USAID, ASDSP KIRDI..

The influence of agricultural product processing strategies on growth of rural women entrepreneurship, according to the key respondents in the 4 counties was that sorting and cleaning was a method used by rural women entrepreneurs. Drying was applied on indigenous vegetables, sweet potatoes, groundnuts, and bananas, 'to make it easy to be ground into flour', according to a key respondent from Kisii county. In Vihiga and Siaya counties sprinkling with water was mainly used on indigenous vegetables to maintain the freshness. Other methods included decorticating groundnuts as mentioned by a key respondent in Siaya County. Juicing was used for mangoes and to some extent sugarcane as mentioned by key respondents from Siaya and Kisii counties, All the Key respondents explained the training areas provided to the entrepreneurs on processing as being on product preservation and food safety measures.

Varieties of food products as mentioned by key respondents were produced after value addition and included peanut butter, chewable cubed shaped sugarcane pieces, mango and sugarcane juice, sweet potato and banana flour, banana and sweet potato crisps and cakes, banana Jam, ripened bananas, banana wine, mats, wall hangings, baskets, purses, all made from banana leaves, 'musherekha' (banana peels burned to ashes). Poultry was valued added to produce chicken parts, defeathered chicken, dressed chicken, fried/ roasted and dried indigenous vegetables. Key 
respondents from Siaya County confirmed that incubation of women entrepreneurs exposed them to technology for processing agricultural products, 'Siaya county ATDS is incubating willing entrepreneurs in groups and as individuals till they established their enterprises, through this they also learn from one another'. The key respondent in Vihiga County informed the researcher that access to machinery was a challenge as the option was to travel to Kisumu and use KIRDI facilities. Access to technology has been a challenge to the rural women entrepreneurs however, a key respondent from Siaya county ATDS explained that they were supporting individual entrepreneurs to purchase prefabricated machineries which were cheaper.

Key respondents mentioned that the Kisii county government had provided solar driers for drying indigenous vegetables among other food products to prolong the 'shelf life' besides providing lights that has enabled a 24 hour economy to thrive in Kisii town. The Kisii county government has supported the youth with loans to purchase motorbikes which provide transport for $60 \%$ of the women entrepreneurs with their wares.

All the key respondents expressed that value addition does not only increase incomes but fetches better prices, triggers increase in number of enterprises and exposes entrepreneurs to technology.

On the Influence of agricultural packaging strategies on growth of women entrepreneurship, key respondents in all the 4 counties mentioned that the use of polythene packaging was very common in Vihiga, Homa bay, Siaya and Kisii counties. The key respondents further mentioned that the packages are in varied sizes and quantities and one of the groups in Homa Bay County reported to be packaging for export where the sweet potatoes are sold at KSHs 45 per kilo fetching KSHs 450,000 weekly for groups. Key respondents explained that trainings have been provided on packaging and quantification, food type packaging, packaging material and Size in the 4 counties. Kisii County has been linked to Kenya Bureau of standards (KEBs) for certification by Kenya Industrial Research Development Institute (KIRDI) as mentioned by key respondents. This resulted in the Ritoke banana crisps in Kisii targeting the international market and already on the shelves of the Nakumatt supermarket.

Key respondents explained that packaging is very expensive but enables ease of sell and opens market channels, including providing varietal products making customers have a wide range of choice. The Kabondo sweet potatoes have also found their way into British snack shops. According to the National Agribusiness strategy, the global exposure could provide an opportunity to be exposed to international standards and develop highly valued food products that fetch a higher income (Republic of Kenya, 2012).

\section{Summary of Findings:-}

Influence of Agricultural products' processing strategy on growth of rural women entrepreneurship:-

Sorting and cleaning was found to be a processing method used by $90.3 \%$ of the respondents, while $68.5 \%$ strongly agreed that they have access to technology for processing food products, $40.6 \%$ strongly agree that they use technology to process food products, $70.9 \%$ strongly agree that processing food products increases monetary value. Majority of the respondents, $(83.7 \%$ ) process food based on the tastes and preferences of customers while $71.0 \%$ agree that they learnt processing methods from other entrepreneurs.

Influence of Agricultural products' packaging strategy on growth of rural women entrepreneurship:-

The , most popular package is the use of polythene bags as $86.6 \%$ strongly agreed, while $92.0 \%$ strongly agreed that packaging food products helps to increase profits. The value of packaging has made the entrepreneurs to attend trainings on packaging strategies as indicated by $96.7 \%$ who agreed and $(96.9 \%)$ agreed that they buy packaging from other companies and since polythene is the main type, these enterprises provide a large market to the manufacturers. On expenditure for purchasing packaging, 91.5\% agreed that they spend at least Kshs 3,000 on packaging which is expensive. Majority of the respondents (90.8\%) expressed that it is the packaging material and design that attracts customers from their counties to buy food products.

\section{Conclusions:-}

Based on the results, a variety of value addition processing methods were used depending on the type of agricultural product and sorting and cleaning was applicable to all agricultural products and used by $90.3 \%$ of the rural women entrepreneurs . Rural women entrepreneurs have access to technology but $40.6 \%$ use it. Agricultural products' processing has been encouraged by the customer value and demand for processed food. The study concludes that processing through the methods, technology use, conforming to customer taste and preferences is a value addition strategy that influences growth of rural women entrepreneurship in western Kenya. Monetary value 
of the agricultural products has increased for $70.9 \%$ of the rural women entreperenuers as a result of value addition through processing. . From the Unstandardized Coefficients, the model predicts that increase in agricultural product processing strategies (.497) would results into increase in Growth of rural women entrepreneurship holding the other independent variable (Packaging strategies) constant.

A variety of packaging were used depending on the type of food but the most dominant were polythene bags bought from manufacture manufacturing companies by $96.9 \%$ of the rural women entreperenuers. The ban on use of polythene paper packaging is a setback to rural women entrepreneurs at the same time an opportunity for creativity and innovativeness on packaging. Rural women entrepreneurs attended trainings on packaging to enable them use appropriate packaging as value addition. The design and materials of the packaging was an attraction for customers to purchase the food products. The conclusion is that appropriate packaging increases the value of the food products in terms of 'place', making it is easier for rural women entrepreneurs to access customers subsequently growth of rural women entrepreneurship as a result of increased profit levels for $92.0 \%$ of the rural entrepreneurs.

Packaging strategies that add value to agricultural products include the type of package, knowledge, attraction to customers and investment. Moreover, increase in Packaging strategies (.185) would results into increase in Growth of rural women entrepreneurship holding the other independent variable (processing strategies) constant.

In conclusion, ANOVA showed the independent variables which includes agricultural product processing $\mathrm{s}$ and Packaging strategies helped to predict the(dependent variable) Growth of rural women entrepreneurship, $(\mathrm{F}=$ 987.397, P (.0005).

\section{Recommendations:-}

The study therefore recommends that to promote growth of rural women entrepreneurship in processing, policymakers should specifically target the breed of technologies that are culturally and socially familiar to women. County governments should provide the infrastructure for processing to support rural women entrepreneurs in value addition activities. Rural women entrepreneurs should be encouraged and supported to be more creative and develop packages using indigenous material that are environment friendly to address the gap that will be created by the recent ban on manufacturing of polythene by the Kenya Government. This will add a unique value to the agricultural products. Development players should create an optimal knowledge system to promote value addition to increase entrepreneurial skills for rural women entrepreneurs by also providing softer lower level financial while ensuring that financial management skills is integrated in agricultural products' processing, and packaging strategies.

Suggestions For Further Research:-Further research is recommended on the, influence of use of social media on rural women entrepreneurship.

\section{References:-}

1. Abukutsa, O, M. (2007). The Diversity of Cultivated African Leafy Vegetables in Three Communities in Western Kenya ${ }^{*}$ African Journal of Food Agriculture Nutrition and Development, ISSN: 1684-5358 EISSN: 1684-5374 Vol. 7, No. 3.

2. Acs, Z. J., and Malecki, E. J. (2003), 'Entrepreneurship in rural America: Growing and Financing Rural Entrepreneurs Centre for the Study of Rural America, Federal Reserve Bank of Kansas City, Kansas City.

3. Anderson, D, P., Daniel Hanselka, D. (2009. Adding Value to Agricultural Products.

4. Alam, S,S., Fauzi,M.,Jani,M., ,Senik,C,Z., ,Khairy,A.,Domil,A.(2011). Assessing Barriers of Growth of Food Processing SMIs in Malaysia: A Factor Analysis. International Business Research Vol. 4, No. 1; January 2011

5. Apata, T, G. (2015). Entrepreneurship processes and small Farms Achievements: Empirical Analysis of Linkage; Journal of Entrepreneurship Management and Innovation (JEMI), Volume 11, Issue 2.

6. Aworh, O. (2008).The Role of Traditional Food Processing Technologies in National Development: The West African Experience; Using Food Science and Technology to Improve Nutrition and Promote National Development,

7. Coltrain, D., D. Barton, and M. Boland. 2000. "Value Added: Opportunities and Strategies." Arthur Capper Cooperative Centre, Department of Agricultural Economics, Kansas State University 
8. Chagomoka,T,T.,Afari-Sefa,V.,\& Pitoro,R.(2013) Value Chain Analysis of Indigenous Vegetables from Malawi and Mozambique; Invited paper presented at the 4th International Conference of the African Association of Agricultural Economists, Hammamet, Tunisia

9. De Bruin, A. M., Brush, C., and Welter, F. (2006), 'Introduction to the Special Issue: Towards building cumulative knowledge on women's entrepreneurship', Entrepreneurship Theory and Practice.

10. De Brentani, U., E.J. Kleinschmidt (2004), Corporate Culture and Commitment: Impact on

11. Performance of International New Product Development Programs. Journal of Product

Innovation Management

12. Envick, R, B., Eileen Wall-Mullen, M, E. (2015) Measuring the Emotional Quality of Products: How Entrepreneurial Firms Can Efficiently and Effectively Improve New Product Development Practices; Journal of Management and Marketing Research

13. GIZ (2013).Post-harvest losses in potato value chains in Kenya; Analysis and recommendations for reduction strategies.

14. Government of Kenya (2012)’National Agribusiness Strategy: Making Kenya's agribusiness sector a competitive driver of growth'.

15. Government of Kenya (2005) Economic Survey of Kenya Report, Government Printer

16. Hussain,S., Saadat,A.,Ibrahim,M.,Noreen,A.,\& Fayaz,S,A. Ahmad.(2015). Impact of Product Packaging on Consumer Perception and Purchase Intention; Journal of Marketing and Consumer Research ISSN 2422-8451 An International Peer-reviewed Journal Vol.10,

17. ILO (2008) Women Entrepreneurs in Kenya; Factors affecting Women Entrepreneurs in Micro and Small Enterprises in Kenya

18. Japan International Cooperation Agency, (2012). The packaging landscape in Kenya: A users' Guide.

19. Kilkenny, M., \& Schluter, G, E. (2001). Value Added Agriculture Policies Across the 50 States." Rural America.

20. Kormawa, P. (2011). Agribusiness: Africa's way out of poverty. Making It Magazine, Industry for Development

21. Kothari, C, R. (2004). 'Research Methodology: Methods and Techniques'; New Age International, New Delhi ( $2^{\text {nd }}$ Edition).

22. Krejcie, V, R., Morgan, W, D. (1970), Determining Sample Size for Research Activities

23. Martella, C, R., Nelson, R, J., Marchand, E, N. (1999). Research Methods; Leraning to become a critical Research Consumer.

24. Mugenda, O. M., \& Mugenda, A. G. (2003).Research methods. Quantitative and qualitative approaches. Nairobi. Acts Press.

25. Mrema, G, C., Ndikumana, J. (2013).Value Addition and Post-harvest Processing in East Africa over the Past Fifty Years and Prospects for the Future.

26. Neven, D. (2014).Developing sustainable food value chains; Guiding principles; FAO, Rome

27. Ntale1, F, J., Litondo, O, K., \& Mapop,.O,M.(2014). 'Indicators of Value Added Agri-Businesses on Small Farms in Kenya: An Empirical Study of Kiambu and Murang'a Counties'; Journal of Small Business and Entrepreneurship Development December 2014, Vol. 2, No. 3 \& 4, ISSN: 2333-6374.

28. Orinda, M. (2013). 'Analysis of factors influencing sweet potato value addition amongst smallholder farmers in Rachuonyo South District, Kenya.'

29. Prakash, D. (2003). Rural women, food security and agricultural cooperatives.

30. Ruoxi L., Dudensing, R. (2015). What Do We Mean by Value-added Agriculture? A publication of the Agricultural and Applied Economics Association

31. Silayoi, P., \& Speece, M. (2006).The importance of packaging attributes: a conjoint analysis Approach. European Journal of Marketing, 41(11), 1495-1517

32. Stathopoulou, S., Psaltopoulos, D., and Skuras, D. (2004), 'Rural entrepreneurship in Europe:

33. A research framework and agenda', International Journal of Entrepreneurial Behaviour and Research, Vol 10, No

34. Ugonna,U,C.,Jolaoso,M,A.,Onwualu,P,A.(2015).Tomato Value Chain in Nigeria: Issues, Challenges and Strategies ; Journal of Scientific Research \& Reports. Article no.JSRR.2015.231 ISSN: 2320-0227

35. Wanga, O, D., Mutuku, M, M., Olubandwa, A, A. (2009)' Value added milk products: Constraints to women in milk micro enterprises in Kenya.' Journal of Development and Agricultural Economics Vol. 1

36. Womach, J. (2005). Agriculture: A Glossary of Terms, Programs, and Laws. 